This item was submitted to Loughborough's Research Repository by the author.

Items in Figshare are protected by copyright, with all rights reserved, unless otherwise indicated.

\title{
Enabling sustainable construction in UK public procurement
}

PLEASE CITE THE PUBLISHED VERSION

http://dx.doi.org/10.1680/mpal.12.00022

PUBLISHER

(C) ICE Publishing Ltd.

VERSION

VoR (Version of Record)

LICENCE

CC BY-NC-ND 4.0

REPOSITORY RECORD

Sourani, Amr, and M. Sohail. 2019. "Enabling Sustainable Construction in UK Public Procurement”. figshare. https://hdl.handle.net/2134/13563. 
This item was submitted to Loughborough's Institutional Repository (https://dspace.lboro.ac.uk/) by the author and is made available under the following Creative Commons Licence conditions.

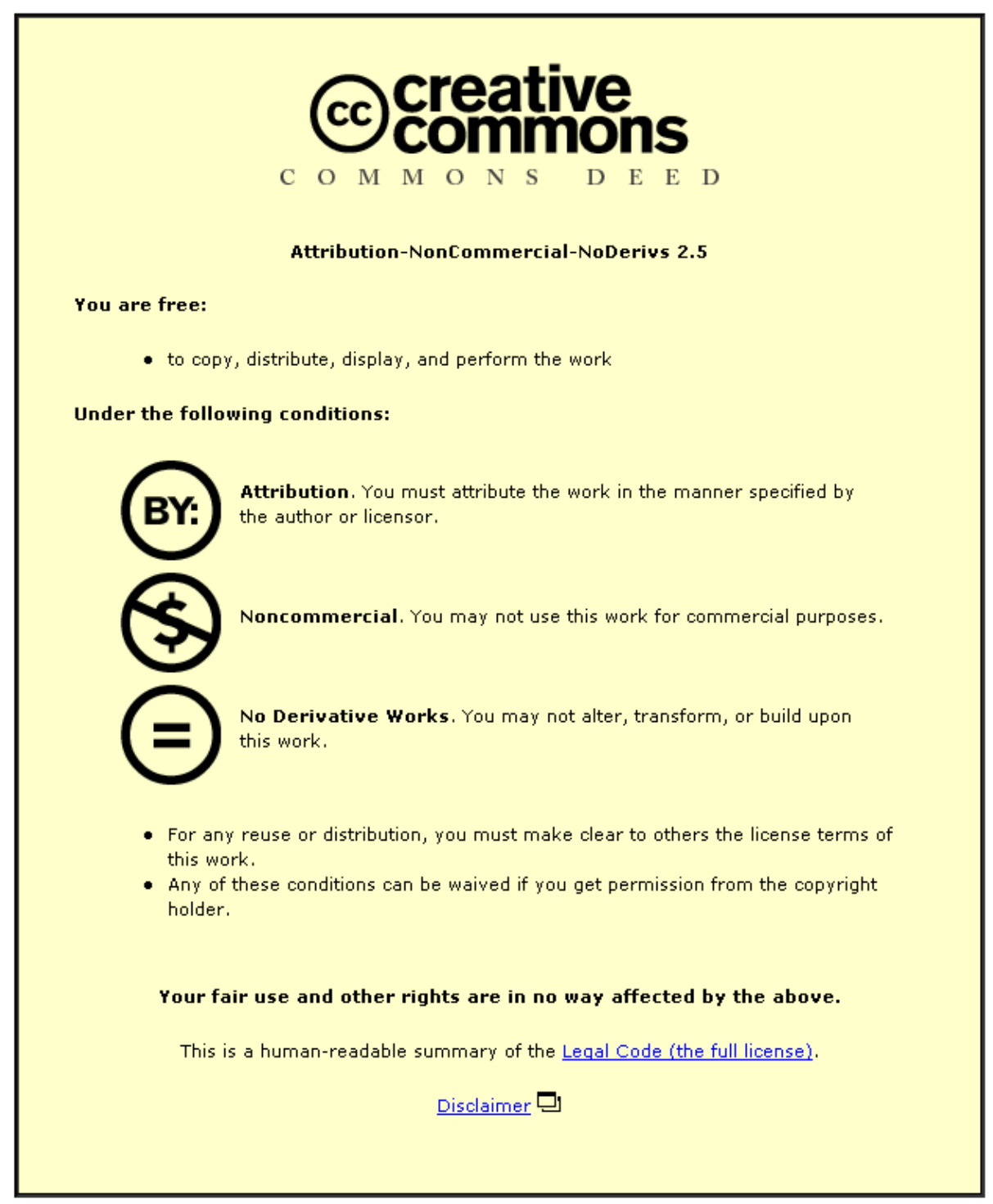

For the full text of this licence, please go to: http://creativecommons.org/licenses/by-nc-nd/2.5/ 
Enabling sustainable construction in UK public procurement

Sourani and Sohail http://dx.doi.org/10.1680/mpal.12.00022

Paper 1200022

Received 20/08/2012

Accepted 26/02/2013

\section{Enabling sustainable construction in UK public procurement}

1 Amr Sourani MSc, PhD

Senior Lecturer in Construction Management, School of the Built Environment, Liverpool John Moores University, UK
2 Muhammad Sohail BEng, MSc, PhD, Fellow ASCE Professor of Sustainable Infrastructure, Director of Research and Enterprise Programmes (WEDC), School of Civil and Building Engineering, Loughborough University, UK

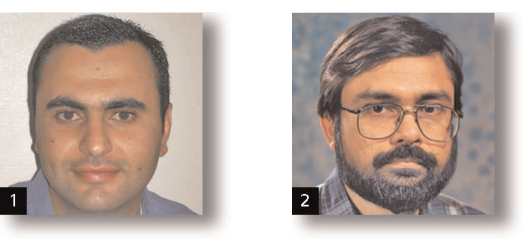

Sustainable construction is about achieving a balance between the social, economic and environmental aspects of construction so that the costs and the benefits, evaluated along these three dimensions, are optimised. Whereas official reports published in the UK have reflected the increasing emphasis on addressing sustainability principles in procurement, the literature suggests that there has been relatively little research on sustainable procurement in the public sector. The aim of this paper is to provide an agreed, comprehensive and evidence-based research into the factors that enable UK public clients to better address sustainable construction in developing procurement strategies. Seeking triangulation, the investigation was conducted using a Delphi exercise and semi-structured interviews/ discussions which involved sustainability professionals and experts. As a result, $\mathbf{4 1}$ factors considered to be important for UK public clients to better address sustainable construction in developing procurement strategies were identified. These were categorised into knowledge and perception factors, organisational and management factors, political and regulative factors, logistical factors, contractual factors, instrumental factors, strategic factors and financial factors.

\section{Background}

Sustainable construction refers to the application of the principles of sustainable development to the construction industry. Despite the variances between definitions, there is a wide acceptance that sustainable construction integrates, at least, three dimensions.

(a) Social dimension: focusing on issues such as health and safety, involvement of stakeholders, equality and diversity in the workplace and creating employment opportunities.

(b) Economic dimension: focusing on issues such as wholelife costing, support of local economies and financial affordability for intended beneficiaries.

(c) Environmental dimension: focusing on issues such as reducing energy and water consumption, using renewable resources and minimising pollution.

Official reports published in the UK have reflected the increasing emphasis on addressing sustainability principles in procurement. In 2007, the government published the Sustainable Procurement Action Plan (Defra, 2007). Among the goals set in the plan was for the UK to be 'among the European Union (EU) leaders in sustainable procurement by 2009' and to achieve 'a low carbon, more resource-efficient public sector' (Defra, 2007: p. 3). For sustainable procurement, the Sustainable Procurement Task Force observed that there was "no consistent definition in use across the public sector that both policy makers and procurement professionals could relate to'. In response, a 'versatile' definition of sustainable procurement, encompassing all three dimensions of sustainable development was devised

\footnotetext{
Sustainable Procurement is a process whereby organisations meet their needs for goods, services, works and utilities in a way that achieves value for money on a whole life basis in terms of generating benefits not only to the organisation, but also to society and the economy, while minimising damage to the environment.

(Sustainable Procurement Task Force, 2006: p. 10).
}

The internal and external pressures to embed sustainability have not translated into widespread establishment of sustainable procurement (Meehan and Bryde, 2011). According to Brammer and Walker (2011), there has been relatively little 
research on sustainable procurement in the public sector. This is consistent with Preuss (2009) who indicated that the academic literature on sustainable procurement is not extensive. Despite the production of several publications addressing the enablers of sustainable procurement, there is little evidence to suggest that these publications provide agreed, comprehensive and evidence-based research into what enables public clients to better address sustainable construction in developing procurement strategies. This paper contributes to covering this knowledge gap through the provision of agreed, comprehensive and evidence-based sets of factors that are important for public clients to better address sustainable construction in developing procurement strategies within the UK context. While this provides the paper's 'academic' contribution to knowledge, the paper involves a 'methodological' contribution through the use of triangulation, which is an appropriate research approach for extending the scope of theory in constructionmanagement research (Love et al., 2002). It facilitates the attainment of convergence in the findings and can allow greater confidence in the reliability and/or the validity of the results (Love et al., 2002). Despite this, there has been reluctance in construction-management research to mix methodologies (Love et al., 2002).

\section{Research methodology}

The type of information sought in this research demands the use of experts. One reason is related to the novelty and complexity of the subject of sustainability. Another reason is related to the expected difficulty that normal practitioners would find in interpreting the subject in general and the additional difficulty arising from requesting them to provide information which is particularly relevant to procurement strategies in the context of the UK public sector. The final reason is related to the 'hybrid' position of Delphi within the qualitative/quantitative debate which places it in an ideal situation for use. Delphi is primarily a qualitative tool that provides a rich context-based knowledge, however, the potential of the technique to provide quantitative results indicates whether consensus can be achieved (Critcher and Gladstone, 1998, cited by Mullen, 2003; MacCarthy and Atthirawong, 2003).

The 'hybrid' position of Delphi highlights its nature in terms of being a self-validating method. Delphi could start with any degree of structure and moves forward in terms of developing that structure. For example, it could initially take an exploratory approach through employing open-ended questions and then takes further structure in consequent rounds. The second round may involve a list of issues that has been generated from analysing the results of the first round and any other issues generated from the literature. Experts may be asked to identify the level of significance or importance of these issues included in the second round. On the third round, experts could be provided with statistical analysis showing their scores and the group score and could then have the opportunity to modify their scores. In this way, every round validates the findings from the previous round. This process in itself could replace a more traditional approach in construction-management research which utilises less-structured methods (e.g. unstructured or semi-structured interviews) at the initial phases of the research and then more-structured methods (e.g. questionnaire survey consisting of closed-ended questions) at a later stage. In other words, Delphi, due to the way it works, could combine two traditional methods in one method.

A triangulated approach utilising experts' knowledge was employed within and across the methods adopted. The factors were established using a Delphi exercise and semi-structured interviews/discussions. Triangulation is an appropriate research approach for extending the scope of theory in constructionmanagement research (Love et al., 2002) as it offers the opportunity to cancel the limitations of one method by using another to cross-check the findings (Bryman and Bell, 2003).

\section{Selection of experts}

Selection of participants (whether for Delphi or for the interviews/discussions) was based on expertise; knowledge was the key criterion to consider. Several indicators of knowledge (Henchion and McIntyre, 2005; Khosrow-Pour and Herman, 2001; Martino, 1983; Scholl et al., 2004; Shon and Swatman, 1998) were taken into account. Among these indicators are

- publications in the field

- signs of professionals' eminence

- peer judgement and recommendations

- honours by professional societies

- self-rating of the expertise

- presentations made at national conventions

- relevant years of experience.

In general, Delphi studies use different sizes of panels. However, it is recognised that a minimum appropriate size would be seven or eight experts. Mitchell and McGoldrick (1994) argued that the size of the panel may be as large as time and money considerations will permit but should have no fewer than eight to ten members. Hallowell and Gambatese (2010) indicated that most studies incorporated eight to sixteen experts and suggested a minimum of eight. However, Hallowell and Gambatese argued that the specific number should be determined by the characteristics of the study. Such characteristics, according to Hallowell and Gambatese, could include the number of available experts, the desired geographic representation and the capability of the facilitator. Hallowell and Gambatese highlighted the importance of having a sufficient number of experts at the end of the Delphi process in light of the possibility of drop-out by some experts (maintaining a high level of response is one of the major difficulties in Delphi, according to Yeung et al., 2009). 
Many Delphi authors share the view that Delphi does not lend itself to random sampling techniques. Such views seem to be consistent with epistemological positions considering Delphi as a rather qualitative approach. But if random sampling is not the right approach to employ, what approach should be taken in selecting experts? In addition to referring to criteria such as knowledge, availability and willingness to participate, many authors tend to choose experts (particularly for the purposes of conducting Delphi) from a variety of backgrounds and positions so that the key viewpoints on the topic are represented (Bendaña et al., 2008; Chan et al., 2001; Henchion and Mclntyre, 2005; Hinks and McNay, 1999; Robinson, 1991; Scholl et al., 2004; Yeung et al., 2009). In this research, the Delphi method involved a panel of experts representing a wide range of views and sectors. The panel involved experts from the public sector, professional/consultancy organisations, major contracting organisations and academics. The results have been further validated through semi-structured interviews/discussions conducted with sustainability experts and professionals working in a variety of professional and publicsector organisations in the UK.

\section{Round one}

The Delphi first-round questionnaire involved questions in an open-ended format to facilitate the exploration of the subject and assist in developing more representative answers of the participants' thinking. The views of the experts who participated in a pilot study supported this approach. As part of the questionnaire, respondents were asked to identify the ways through which UK public clients can better address sustainable construction in developing a procurement strategy. Twenty-one experts were contacted and seventeen replies were received (representing a response rate of $81 \%$ ). These were widely distributed among the participating groups, thus providing a balanced view and an appropriate presentation of the groups (Chan et al., 2001; Robinson, 1991). Any non-response was mainly due to the experts' workload. Similar difficulty was reported in other Delphi studies such as Chan et al. (2001). The analysis of the results obtained in the first round led to the identification of 36 factors (factors F1 to F36 in Table 1).

\section{Round two}

Based on the analysis of the results obtained from round one, the Delphi second-round questionnaire was developed. Respondents were asked to assess the level of importance of the 36 factors obtained from round one, using a five-point Likert scale ranging from 1 denoting 'not important' to 5 denoting 'extremely important'. Experts were also asked to add any other factors that were not listed, to identify their level of importance and to add any comments. Fifteen replies were received in this round. Two experts were not able to respond due to workload. This, however, did not affect the overall balanced composition of the panel. The analysis of the results led to the identification of the level of importance of the 36 factors included in the second-round questionnaire and to the identification of one new factor (F37). For each of the 36 factors, the mean and the standard-deviation values of the scores provided by the experts in the second round were calculated.

\section{Round three}

Based on the analysis of the results obtained from round two, the Delphi third-round questionnaire was developed. Respondents were given feedback from the second round which involved presenting the factors F1 to F36 with two scores indicating their level of importance. The first score was named 'your score' and represented the score that the expert provided in round two regarding the level of importance of the factor while the second score was named 'mean score' and represented the mean of the scores provided by all the experts who participated in round two regarding the level of importance of the factor. In the third round, experts had the opportunity to reconsider the scores they provided in the second round using the same five-point Likert scale and to assess the level of importance of the factor F37, which was identified from the second round. Thirteen replies were received in this round. Again, due to workload, two experts were unable to respond. This did not affect the overall balanced composition of the panel.

\section{Establishing factors using Delphi}

Based on the responses to the Delphi third-round questionnaire, the values for the mean and the standard deviation of the scores assigned to each factor were calculated and the factors were then ranked. In addition, the percentage of respondents agreeing on the ranking of a factor was identified (Table 1).

A factor with a value of mean that is equal to or above 3 can be considered important (based on the Likert scale used).

Agreement among respondents that a certain factor is important can be established based on having $75 \%$ or more of the respondents agreeing on a ranking that is equal to or above 3 (i.e. a ranking of $3=$ moderately important, $4=$ very important or $5=$ extremely important). The values shown in column 11 of Table 1 show the percentages of respondents agreeing on ranking that is equal to or above 3 .

The standard-deviation values shown in Table 1 can be considered relatively low (therefore indicating agreement).

Factors that satisfy the above indicators include 36 out of the 37 factors included in round three. These factors scored mean values above 3 ; were rated by $75 \%$ of the experts or more as moderately, very or extremely important; and had relatively low values of standard deviation. One factor (F26) was omitted as only $69 \cdot 23 \%$ of experts agreed that it was important. 


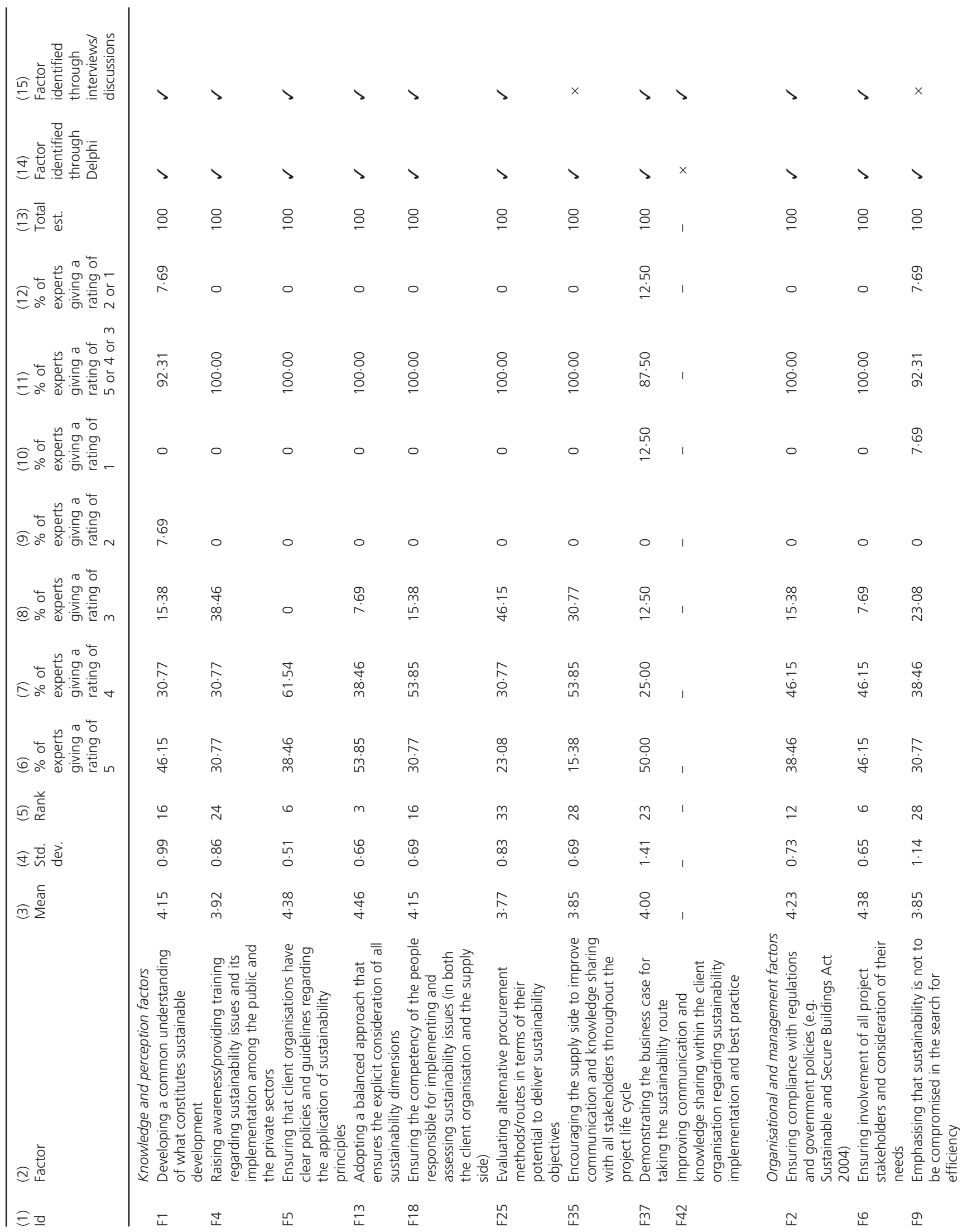




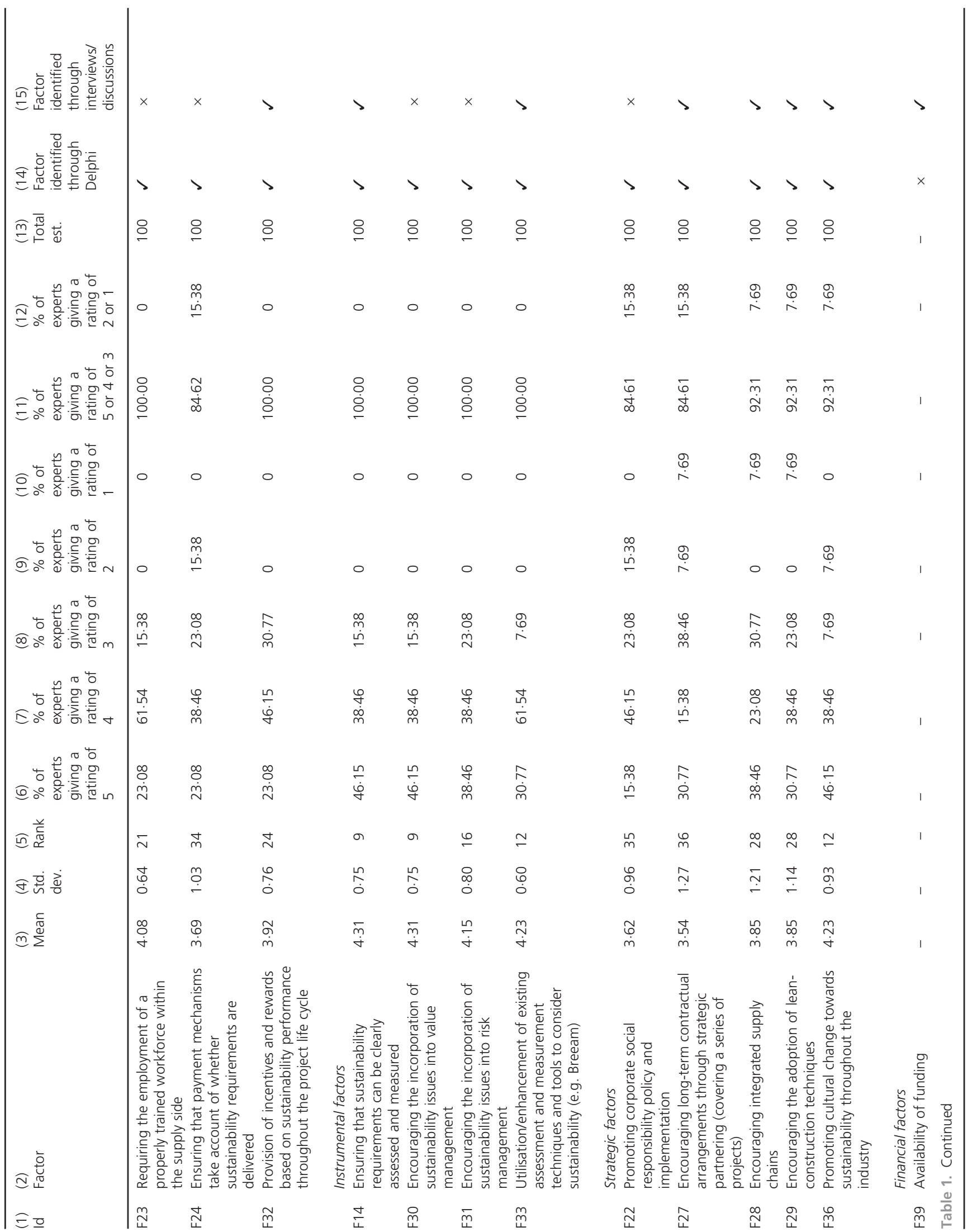




\section{Further validation using interviews and discussions}

The results obtained from Delphi were further validated through twelve semi-structured interviews and discussions conducted with sustainability experts and professionals working in a variety of professional and public-sector organisations in the UK. The results obtained from the interviews/ discussions were compared with the results obtained from Delphi. This led to the following findings (Table 1).

- Confirmation of a number of factors obtained through Delphi. Twenty-five of the factors that had been identified through Delphi were confirmed by the interviews/ discussions (factors F1 to F8, F10, F12 to F14, F16 to F20, F25, F27 to F29, F32 to F33, F36 to F37).

- Identification of new factors that were not identified through Delphi. Five additional factors that had not been identified through Delphi were identified through the interviews/ discussions (factors F38, F39, F40, F41 and F42).

In total, 41 factors were obtained from the Delphi exercise, the interviews/discussions or both. The factors were categorised into eight main categories (Table 1)

actors

- organisational and management factors

- political and regulative factors

- logistical factors

- contractual factors

- instrumental factors

- strategic factors

- financial factors.

\subsection{Knowledge and perception factors}

As shown in Table 1, this category includes nine factors. Two of these were rated by the Delphi experts among the most important ten factors. These include the factors F5 (ranked sixth with a mean of 4.38) and F13 (ranked third with a mean of 4.46). One of the additional factors from those that were identified through the interviews/discussions (F42) is also within this category. All factors within this category are discussed below.

\section{F1: Developing a common understanding of what} constitutes sustainable development

Public clients need a common understanding regarding sustainability criteria. Sustainability has a huge scope and therefore it is difficult to capture all the issues included within this scope. Furthermore, sustainable development is still perceived by some as an environmental problem. Problems related to how sustainability is being perceived have been well documented in the literature (e.g. Adetunji et al. 2003; Carter and Fortune, 2002; Environmental Audit Committee, 2005; Hawkins and Shaw, 2004).
F4: Raising awareness/providing training regarding sustainability issues and its implementation among the public and the private sectors

Further training on sustainability issues, particularly at the level of senior procurement decision makers, needs to be provided. The sustainability concept needs to be broken down from the abstract level to facilitate a better understanding and implementation of sustainability in the context of construction projects.

F5: Ensuring that client organisations have clear policies and guidelines regarding the application of sustainability principles

There is a need for more government steering, simpler and more structured guidance and more demonstrations, tools and techniques. Confronting public clients with huge amounts of guidance that do not clearly illustrate 'what needs to be done' and 'how to do it' was not helpful. The need for clearer guidance may have resulted from political views which try to avoid prescription and advocate the specification of targets, leaving it to individual organisations to determine how best to meet these targets.

\section{F13: Adopting a balanced approach that ensures the explicit consideration of all sustainability dimensions}

The emphasis given to certain sustainability dimensions at the expense of other dimensions has been indicated by the literature (e.g. Carter and Fortune, 2002; IDeA, 2003). Sustainability may still be perceived as an environmental problem. When such a perception exists in organisations dominated by economic drivers, the social dimension would expectedly become the most negligible dimension.

F18: Ensuring the competency of the people responsible for implementing and assessing sustainability issues (in both the client organisation and the supply side) OGC (2005) highlights the need to ensure that the supply teams have skilled and experienced resources to implement sustainable projects. This also applies to the client side. With political views which tend to specify targets and give organisations the freedom to determine how best to meet these targets, the issue of having experienced in-house people who are competent to assess sustainability issues becomes of particular importance.

F25: Evaluating alternative procurement methods/routes in terms of their potential to deliver sustainability objectives

It does not seem that sustainability represents a key aspect in selecting a procurement route. This may be attributed to the ambiguity regarding whether procurement routes have different potential to deliver sustainability. No procurement route is clearly and consistently better than other routes regarding the potential to deliver environmental objectives (Addis and Talbot, 2001). Procurement routes, however, have shown 
different potential to deliver economic objectives such as time and cost (Alhazmi and McCaffer, 2000; Ambrose and Tucker, 2000; Love et al., 1998). Whether these routes have different potential to deliver social sustainability remains unclear.

\section{F35: Encouraging the supply side to improve} communication and knowledge sharing with all stakeholders throughout the project life cycle

Public clients need to consider the willingness and the ability of the supply team to educate the different stakeholders and provide handover training (OGC, 2005). For example, facility users may need to be educated on how to contribute to achieving sustainability through conserving water, reducing energy consumption and minimising waste.

\section{F37: Demonstrating the business case for taking the sustainability route}

Clients need to understand that adopting sustainability could create buildings with happier, healthier, less-absent and moreproductive occupants; lower life cycle costs and less environmental impacts. Contractors need to understand sustainability benefits and appreciate the legislative pressure, market forces, investor concerns and client demand (Sustainable Construction Task Group, 2001). This could encourage contractors to develop internal policies (e.g. training and development policies) and respond to sustainability requirements included in tender documents more innovatively.

\section{F42: Improving communication and knowledge sharing within the client organisation regarding sustainability implementation and best practice}

Even if best practice regarding sustainability and its implementation is available, it may not be shared between the various departments within the client organisation. Links between sustainability and procurement professionals should be established.

\subsection{Organisational and management factors}

This category includes eight factors. Three of these were rated by the Delphi experts as being among the most important ten factors. These include the factor F6 (ranked sixth with a mean of 4.38) and the factors F11 and F17 (both ranked third with a mean of 4.46). One of the additional factors from those that were identified through the interviews/discussions (F41) is also within this category. All factors within this category are discussed below.

\section{F2: Ensuring compliance with regulations and government policies (e.g. Sustainable and Secure Buildings Act 2004) \\ Some of the relevant government policies are presented through} government publications, action plans and codes of practice. Examples include Part L of the building regulations, European
Union energy performance building directive, the code for sustainable buildings and the strategy for sustainable construction. However, the incorporation of some sustainability issues remains optional and there may be a need for a more mandatory role in order to better address sustainability, as shown below in the discussion of factor F40.

\section{F6: Ensuring involvement of all project stakeholders and consideration of their needs}

All project stakeholders whether external or internal (i.e. the different groups within the client organisation) should be involved. All these could influence the budget and need to understand the benefits of adopting a sustainability route.

\section{F9: Emphasising that sustainability is not to be compromised in the search for efficiency}

Public clients' policies and codes of practice need to reflect the balance that sustainability tries to achieve. Social and environmental considerations should not be compromised in favour of more cost-effective solutions. This would have consequences on all project aspects including design, specification and selection of contractors.

\section{F11: Ensuring the consideration of a complete range of options to meet the need (e.g. refurbishment, new build)}

If the need can be met through refurbishing an existing building, more cost-effective solutions and less negative environmental and social impacts could be achieved through this option than through the option of new build.

\section{F15: Ensuring transparency in procurement decision making}

Clear and comprehensive coverage and proper weighting of sustainability issues should be facilitated within procurement decision making.

\section{F17: Ensuring the consideration of whole-life costing/ value}

Whole-life costing exercises enable the minimisation of the social and environmental impacts of the products throughout their lifetime and facilitate a better understanding of the true financial implications of procurement decisions (IDeA, 2003). Whole-life costing helps in justifying initial capital investments in sustainable products which bring long-term benefits (e.g. energy-saving measures).

F34: Requiring reviews to be conducted to monitor the delivery of sustainability requirements throughout the project life cycle

Periodic reviews of sustainability performance should be conducted during the construction process (OGC, 2005). This should be considered in contract preparation. 


\section{F41: Facilitating publicity of actions taken by public procurers towards addressing the sustainability agenda}

Publicity of the work undertaken by public clients in relation to sustainable procurement could motivate these clients and other clients to adopt similar approaches.

\subsection{Political and regulative factors}

This category includes three factors. No factor within this category was rated by the Delphi experts among the most important ten factors. Two of the additional factors from those that were identified through the interviews/discussions (F38 and F40) are within this category. All factors within this category are discussed below.

\section{F3: Highlighting the need for regulations and government policies that are more consistent with sustainability}

Concerns were reported about possible inconsistency between the different sustainability publications (whether produced by the government or by other bodies). While there is scope to do more by most bodies within existing legislation, this legislation may be regarded as restrictive to certain organisations which have high standards of sustainable procurement and want to do more, particularly in relation to social issues (Environmental Audit Committee, 2005).

F38: Greater focus, joined-up thinking, leadership, and commitment by the government

The strict requirements on expenditure imposed by the Treasury were seen as restrictive for public-sector organisations to think long term. There may be a need for more joined-up thinking between government departments.

\section{F40: Introducing more mandatory influence}

As shown in the discussion of the factor F2, the incorporation of some sustainability issues remains optional in some of the current codes of practice; hence progress may not be quick enough. By enforcing sustainability requirements, organisations would have no choice but to respond. The scope of regulations could be extended to incorporate a wider range of sustainability issues, such as those outlined in the OGC's guide Sustainability (OGC, 2005). This could help in creating a level playing field to enable competition on equal terms. However, this could create common but fairly low standards that may not go beyond legal requirements.

\subsection{Logistical factors}

This category includes two factors. Both were rated by the Delphi experts among the most important ten factors. These include the factors F7 (ranked first with a mean of 4.54) and F8 (ranked ninth with a mean of 4.31). Both factors are discussed below.
F7: Ensuring timely involvement of project stakeholders Interests of project stakeholders should be considered as early as possible. Late consultations may not enable accommodating the needs of stakeholders and significant costs may be incurred.

\section{F8: Allowing sufficient time in the programme to address and assess sustainability issues}

Sufficient time should be given to address and measure sustainability issues (e.g. when attempting to accommodate sustainable solutions within the contract specification).

\subsection{Contractual factors}

This category includes nine factors. Two factors were rated by the Delphi experts among the most important ten factors. These include the factors F12 (ranked first with a mean of 4.54) and F16 (ranked sixth with a mean of 4.38). All factors within this category are discussed below.

\section{F10: Highlighting sustainability in the project brief as a primary aim}

The project brief describes the completed project, the expected outcome, the role of contractor, the constraints and the difficulties. Integrating sustainability into the project brief enables the presentation of sustainability in a way that cannot be ignored at any of the project-delivery stages (Sourani and Sohail, 2005).

\section{F12: Integrating sustainability requirements into contract specifications and conditions (including specifying any project-specific sustainability requirements)}

The importance of developing specifications in which sustainability is integrated has been well documented (e.g. Addis and Talbot, 2001; Environmental Audit Committee, 2005; OGC, 2005). The separation of capital cost from other life-cycle costs could have a negative impact on developing specifications addressing sustainability. If there is an interest in reducing the capital cost but no interest in reducing other life-cycle costs, less-sustainable products and materials may be specified.

\section{F16: Emphasising the importance of sustainability in tender evaluation and selection procedures}

Sustainability should be a vital part of pre-qualification and tender assessment; tenderers should be asked to provide full details of how they will respond to sustainability requirements and the importance of this element in tender appraisal should be made clear (OGC, 2005).

F19: Requirement/incentive for the supply side to demonstrate commitment to sustainable development through policy and implementation Contractor's commitment to sustainability is significantly influenced by client's demand. Examples of what evidence could establish an organisation's commitment to sustainability could include (Addis and Talbot, 2001): sustainability policy 
and its linkage to business goals and strategy, environmental policy, corporate social responsibility policy and environmental-management systems.

F20: Requiring the supply side to demonstrate capability of delivering sustainability requirements

Contractors should demonstrate possession of the required resources to achieve outcomes and provide examples of successfully completed sustainable projects. Site visits could be used to examine the delivery of these projects (OGC, 2005). This could include questioning owners and users about the construction and the operation of the facility. The supply team's suitability to deliver sustainability should be assessed in a clear and methodical manner.

\section{F21: Encouraging tenderers to suggest innovative} solutions and approaches that support the client's overall sustainability objectives

Tender documentation can be developed in a way that encourages suppliers to provide innovative sustainability solutions. Tenderers could be asked to show in a separate section how they will meet or exceed the specified sustainability objectives (OGC, 2005).

\section{F23: Requiring the employment of a properly trained workforce within the supply side}

It is the workforce that would carry out the operations through which sustainability objectives could be achieved. OGC (2005) shows the importance of having commitment from the supply side towards their workforce and towards achieving the Respect for People Standards and providing all site staff and subcontractors with proper training in environmental awareness.

\section{F24: Ensuring that payment mechanisms take account of} whether sustainability requirements are delivered

Linking payment mechanisms to whether or not sustainability requirements are delivered creates an incentive for the contractor to deliver these requirements. This is consistent with the demand by OGC for public clients to induct sustainability key performance indicators into payment mechanisms during the contract-preparation process (OGC, 2005).

\section{F32: Provision of incentives and rewards based on sustainability performance throughout the project life cycle}

Incentives and rewards are means by which change can be driven to the industry (Kenley et al., 2000). Encouraging contractors at the tender stage to identify sustainable solutions could result in life-cycle savings (Casella Stanger et al., 2002). These could then be shared through a certain mechanism. In private finance initiative projects, for example, if the client and the contractor have shares in paying energy bills over the facility's life cycle, then both parties may have an interest in investing in energy-conservation measures.

\subsection{Instrumental factors}

This category includes four factors. Two factors were rated by the Delphi experts among the most important ten factors. These include the factors F14 and F30 (both ranked ninth with a mean of 4.31). All factors within this category are discussed below.

\section{F14: Ensuring that sustainability requirements can be clearly assessed and measured}

Although tools and indicators, such as the Respect for People toolkits and Breeam, could be helpful in assessing certain aspects of sustainability, they are not sufficiently comprehensive to address the whole sustainability agenda. Moreover, there is a lack of tools and mechanisms to support addressing sustainability in procurement decision making (e.g. assessment of a contractor's performance regarding sustainability).

\section{F30: Encouraging the incorporation of sustainability} issues into value management

Utilising value management for the purpose of reducing costs could lead to the use of cheaper but less-sustainable materials. Value management could be rather used in a way that enhances the integration of sustainability issues into the planning process; for example, sustainability issues should be given high priority when prioritising key objectives in a value tree (Addis and Talbot, 2001).

\section{F31: Encouraging the incorporation of sustainability issues into risk management}

Delivering sustainability through procurement strategies could involve the identification of sustainability-linked risks and the most appropriate party to manage these (Addis and Talbot, 2001). The scope of risk management could be extended to deal with the whole range of social, economic and environmental aspects.

\section{F33: Utilisation/enhancement of existing assessment and measurement techniques and tools to consider sustainability (e.g. Breeam)}

None of the existing tools or techniques seems to be sufficiently comprehensive in terms of addressing all criteria underpinning the social, economic and environmental dimensions. There is a growing need to develop simple but comprehensive techniques and tools focusing on sustainability criteria.

\subsection{Strategic factors}

This category includes five factors. No factor within this category was rated by the Delphi experts among the most important ten factors. All factors within this category are discussed below. 


\section{F22: Promoting corporate social responsibility policy and implementation}

Corporate social responsibility (CSR) shows how a business considers its social, economic and environmental impacts in the way in which it operates. Best-practice guidance, intelligent regulation and fiscal incentives are instruments that could be used by the government to encourage the adoption of CSR (Department for Business Innovation and Skills, 2012). One way through which tenderers can demonstrate commitment to CSR is by registering to the Considerate Constructors Scheme (Considerate Constructors Scheme, 2005).

\section{F27: Encouraging long-term contractual arrangements through strategic partnering (covering a series of projects)}

Concerns were reported in the literature (NAO, 2005) about the risk of absence of competitive and commercial tension in longer-term framework contracts and partnering arrangements, hence not achieving a fair price. Openness, transparency and adequate measurement are therefore crucial to deliver best value (NAO, 2005). The partnering philosophy could be further extended and employed with all stakeholders (Addis and Talbot, 2001), thereby bringing social and environmental benefits.

\section{F28: Encouraging integrated supply chains}

The majority of the companies constituting the construction industry are small organisations with very limited resources. In such a fragmented environment, it is difficult to think beyond short-term interests. Achieving more integration in the industry could increase the likelihood of having longer-term perspective and therefore could encourage the incorporation of sustainability issues.

\section{F29: Encouraging the adoption of lean-construction techniques}

Lean construction is a cross-cutting theme that affects delivering certain sustainability criteria. For example, lean construction helps obtaining better quality, improving efficiency in the use of resources, reducing and managing waste, achieving cost and time savings, and realising value for money (Constructing Excellence, 2004; GCCP, 2000; Highways Agency, 2003; Rethinking Construction, 2003).

\section{F36: Promoting cultural change towards sustainability throughout the industry}

The construction industry can be considered 'inherently defensive' about change (CIB, 1999). Government clients have a key role in introducing cultural change through raising awareness and education of the different parties, best-practice guidance, recognition of the business case for better social and environmental performance, and competition pressure (DETR, 2000).

\subsection{Financial factors}

This category includes one factor only (F39). The factor included in this category (F39) is among the additional factors that were identified through the interviews/discussions. This factor is discussed below.

\section{F39: Availability of funding}

The reduction of the funding available for the public sector could have a negative impact as more initial capital expenditure may be required to invest in sustainable solutions. The business case for taking the sustainability route needs to be demonstrated for all stakeholders (including financers).

\section{Limitations}

The main limitation of this study is related to the number of factors that were identified as important in order to better address sustainable construction in developing procurement strategies. As a large number of factors have been identified through the Delphi exercise, it might be argued that these factors could be condensed to result in a more concise list. However, there are two reasons behind this. First, the authors took the view that the researcher role as a moderator within a Delphi study should involve minimum interference in relation to representing the panel of experts' points of views and therefore a long list of factors has been obtained as a result of the analysis. Second, the authors took the view that any list of factors resulting from the analysis would be validated throughout the different rounds of the Delphi exercise and through the interviews/discussions; it was estimated that this would give the respondents the opportunity to omit any factors by identifying them as factors which have no importance, to make any comments on any of the factors included or to identify new factors. One way to deal with the problem of having a long list of factors was to categorise them. This categorisation was undertaken after conducting the Delphi exercise. However, it might have been more appropriate to categorise the factors throughout the Delphi exercise as this could have provided the respondents with a clearer presentation of the factors.

A point to note is that a factor can be classified in more than one category. For example, the factor 'raising awareness/providing training regarding sustainability issues and its implementation among the public and the private sectors' can be considered among the knowledge and perception factors and also among the organisational and management factors. Therefore, the categorisation introduced should be treated as illustrative rather than definitive. Another point to note is the consistency of the categorisation undertaken in this study with the categorisation of the facilitators of sustainable procurement in the international comparative study undertaken by Brammer and Walker (2011), which categorised the facilitators into 'knowledge/expertise', 'leadership', 'individual/personal commitment', 
'legislation/government support', 'absence of a financial hurdle', 'presence of planning, strategies and goal setting'.

\section{Conclusion and implications}

Adopting a triangulation approach, the factors which are important for UK public clients to better address sustainable construction in developing a procurement strategy were identified using a Delphi exercise and semi-structured interviews/ discussions with experts and professionals. In total, 41 factors were identified. Among these, 25 factors were obtained by the Delphi exercise and confirmed by interviews/discussions, 11 factors were obtained by Delphi only and five factors were obtained by the interviews/discussions only. The factors were categorised into eight main categories. These included knowledge and perception factors, organisational and management factors, political and regulative factors, contractual factors, instrumental factors, consistency of sequence of factor categories, strategic factors, and financial factors.

The most important ten factors, based on Delphi, and the five additional factors that were identified through the interviews and discussions were distributed among the majority of these categories. The categories which comprise these factors are listed below.

- Knowledge and perception factors. Ensuring that client organisations have clear policies and guidelines regarding the application of sustainability principles; adopting a balanced approach that ensures the explicit consideration of all sustainability dimensions; and improving communication and knowledge sharing within the client organisation regarding sustainability implementation and best practice.

The findings confirm what has been established by the literature, which indicated that the concept of sustainable development has been misunderstood (Carter and Fortune, 2007) and perceived differently (Preuss, 2009). The literature emphasised the need to develop a common understanding of the individual features of sustainabledevelopment policies and how these are addressed at the building-project level (Carter and Fortune, 2007). The findings also confirm the lack of a balanced approach in terms of the consideration given to the dimensions of sustainability, an issue that has been frequently indicated in the literature (Carter and Fortune, 2007). It was observed that the environmental, economic and social aspects of sustainability have not been given equal weighting in procurement, with emphasis on environmental issues (Carter and Fortune, 2007; Meehan and Bryde, 2011). This implies, as recommended by Preuss (2009; citing Defra, 2006), that the public sector should move beyond the focus on environmental issues towards addressing a more holistic view of sustainability aspects through procurement. The findings are also consistent with what has been reported by Carter and Fortune (2007), who observed an overwhelming amount of advice and guidance on how to deliver sustainability, and with Preuss (2009), who argued that sustainable procurement initiatives would call on the expertise of sustainability and procurement staff. The results of the study by Thomson and Jackson (2007) show that local authorities provided information on green procurement to relevant staff using various combinations of intranet, newsletters, handbooks, guidelines and meetings to raise awareness and share experience; used forums addressing specific procurement issues and employed environmental champions. Thomson and Jackson (2007) highlighted a number of measures used by local authorities to inform green procurement decisions. Among these are eco-labelling, ratings, industry labels and accreditations, life-cycle assessment information, preference examples, standards, environmental-performance information and best-practice examples (Thomson and Jackson, 2007).

- Organisational and management factors. Ensuring involvement of all project stakeholders and consideration of their needs; ensuring the consideration of a complete range of options to meet the need (e.g. refurbishment, new build); ensuring the consideration of whole-life costing/ value; and facilitating publicity of actions taken by public procurers towards addressing the sustainability agenda. The literature indicated that the concept of sustainable development had been unsupported by many stakeholders (Thomson and Jackson, 2007). Procurement decisions are still being based on price rather than on whole-life costing, which is preferred by the UK government (Thomson and Jackson, 2007). The literature also indicates that top-management commitment is a leading facilitator for sustainable procurement (Walker and Brammer, 2009). Green procurement could be strengthened if it can be shown how it can contribute towards organisational objectives and if benefits are quantified (Thomson and Jackson, 2007).

- Political and regulative factors. Greater focus, joined-up thinking, leadership, and commitment by the government; and introducing more mandatory influence.

The policy regarding public procurement in the UK, which is considered among the leading countries in sustainable procurement, is based on guiding principles that include transparency, competitiveness, accountability, efficiency, legality and integrity with the ultimate aim of delivering value for money (Brammer and Walker, 2011). A number of reports shaping the debate on sustainable procurement (see Thomson and Jackson, 2007) for a summary of outcomes of these reports) and legislation related to sustainability in construction and the built environment (see Akbiyikli et al., 2012) have been 
published. Whereas sustainable procurement has been encouraged by way of legislation and providing information (Brammer and Walker, 2011; Thomson and Jackson, 2007), public procurement needs to become more consistent with sustainability. Thomson and Jackson (2007) reported complaints from private-sector suppliers that their efforts to offer more-sustainable products were repeatedly rejected by public procurers and indicated that the public sector was lagging behind private-sector practice. Procurement decision makers find it easier to justify decisions based on price rather than on consideration of wider social, economic and environmental benefits (Thomson and Jackson, 2007).

A key challenge in this regard arises from the implications of EU procurement directives. For example, there may be a concern for buying local from the perspective of promoting competition across the EU (Walker and Brammer, 2009). However, there is scope within the directives to make a contribution to sustainability; a ruling by the European Court of Justice indicates that environmental and social criteria can be used in assessing the most economically advantageous tender (MEAT) but they may only be applied where they do not violate the principles of non-discrimination among EU member states (Preuss, 2009). The EC Interpretative Communication set out potential trade-offs between environmental and social objectives and economic objectives without transgressing EC (EU) principles (Thomson and Jackson, 2007). Useful lessons may also be learnt from leading countries in sustainable procurement such as Japan, which developed eco-labelling, purchasing guidelines, product lists, economic instruments, a mandatory reporting system, life-cycle analysis information and a public-awareness programme (Thomson and Jackson, 2007).

- Logistical factors. Ensuring timely involvement of project stakeholders; and allowing sufficient time in the programme to address and assess sustainability issues. An interesting point to note is that despite the importance of the logistical factors as indicated by the results of the Delphi exercise, no clear support has been found in the literature with regard to these factors.

- Contractual factors. Integrating sustainability requirements into contract specifications and conditions (including specifying any project-specific sustainability requirements); and emphasising the importance of sustainability in tender evaluation and selection procedures.

The findings are consistent with the literature in terms of the need to utilise contractual documentation and procedures to obtain sustainable procurement. For example, Eadie et al. (2011) highlighted how stages of procurement ease tackling social issues (e.g. in terms of specification, selection and award procedures). In the case studies researched by Preuss (2009) to explore the ways in which local authorities deliver/foster sustainable development, Preuss highlighted the use of sustainable design features, the specification of minimum recycled content for building material, risk assessment, training on how to effectively include requirements in contracts, certification to ISO 14001 (BSI, 2004) or the EU scheme EMAS, and the use of sustainability-management questionnaires targeting suppliers. The study by Thomson and Jackson (2007) involves useful information about the type of specification possible under European procurement rules with links to various stages of the project. The study by Thomson and Jackson indicates that procurement decision makers could consider the need for documentary evidence of environmental performance and impact on wider strategic goals and highlights the need for financial instruments to reward environmental benefits.

- Instrumental factors. Ensuring that sustainability requirements can be clearly assessed and measured; and encouraging the incorporation of sustainability issues into value management.

The findings are consistent with the literature which highlighted the importance of tools in making sustainable procurement happen (Brammer and Walker, 2011) and indicated the need to develop a small number of indicators of sustainable development that are specific and applicable to procurement (Meehan and Bryde, 2011); current tools and indicators are too many and too broad, aiming at policy-level thinking, overly complex - detailing vast lists of action and heavily focused on environmental issues (e.g. eco-homes) (Carter and Fortune, 2007).

- Financial factors. Availability of funding. Availability of funding is of paramount importance to deliver sustainable procurement; the literature indicates that cost is the leading barrier to sustainable procurement (Sourani and Sohail, 2011; Walker and Brammer, 2009), particularly with the impact of recession. Although sustainability has always been perceived to be more expensive (Brammer and Walker, 2011), it does not always have to cost more (Preuss, 2009). Even where sustainability proves to be more expensive in terms of capital cost, it should be noted that with the adoption of a long-term perspective, an organisation's sustainability performance could make further contribution to business competitiveness in the future (Tan et al., 2011). As mentioned earlier, sustainable procurement could be supported if it is shown how it can contribute towards organisational objectives and if benefits are quantified (Thomson and Jackson, 2007). Lessons need to be learnt from industry sectors that have made good progress in embedding sustainability (Meehan and Bryde, 2011).

The contribution of this paper to the existing body of knowledge is twofold: academic and methodological. Academically, 
despite the production of several publications addressing the enablers of sustainable procurement, there is little evidence to suggest that these publications provided agreed, comprehensive and evidence-based sets of factors that are important for public clients to better address sustainable construction in developing a procurement strategy. This paper has contributed to the coverage of this knowledge gap.

The methodological contribution has been made through the use of triangulation. Although triangulation facilitates the attainment of convergence in the findings and allows greater confidence in the reliability and/or validity of the results, there has been reluctance in construction-management research to mix methodologies (Love et al., 2002). This may be viewed as part of a bigger problem related to management research in general. It has been shown that management researchers were compromising triangulations and that internal, external and construct validity declined (Bryman and Bell, 2003). Management research may be moving even further away from rigour, and limiting the applicability of findings by failing to triangulate. This paper has contributed to overcoming such a problem through the adoption of a triangulated approach; the paper has employed more than one technique to achieve the objectives.

\section{REFERENCES}

Addis B and Talbot R (2001) Sustainable Construction Procurement: A Guide to Delivering Environmentally Responsible Projects. Ciria, London, UK, Ciria C571.

Adetunji I, Price A, Fleming P and Kemp P (2003)

Sustainability and the UK construction industry - a review. Proceedings of the Institution of Civil Engineers Engineering Sustainability 156(4): 185-199.

Akbiyikli R, Eaton D and Dikmen S (2012) Achieving sustainable construction within Private Finance Initiative (PFI) road projects in the UK. Technological and Economic Development of Economy 18(2): 207-229.

Alhazmi T and McCaffer R (2000) Project procurement system selection model. Journal of Construction Engineering and Management 126(3): 176-184.

Ambrose MD and Tucker SN (2000) Procurement system evaluation for the construction industry. Journal of Construction Procurement 6(2): 121-134.

Bendaña R, del Caño A and de la Cruz MP (2008) Contractor selection: fuzzy control approach. Canadian Journal of Civil Engineering 35(5): 473-486.

Brammer S and Walker H (2011) Sustainable procurement in the public sector: an international comparative study. International Journal of Operations \& Production Management 31(4): 452-476.

Bryman A and Bell E (2003) Business Research Methods. Oxford University Press, New York, NY, USA.
BSI (2004) BS EN ISO 14001:2004: Environmental management systems. Requirements with guidance for use. BSI, Milton Keynes, UK.

Carter K and Fortune C (2002) Towards an understanding of sustainability in social housing projects. Proceedings of the RICS Foundation Construction and Building Research Conference, Nottingham Trent University, Nottingham, UK, 5-6 September.

Carter K and Fortune C (2007) Sustainable development policy perceptions and practice in the UK social housing sector. Construction Management and Economics 25(4): 399-408.

Casella Stanger, DTI, Forum for the Future and Carillion (2002) Sustainability Accounting in the Construction Industry. Ciria Publishing Services, London, UK.

Chan APC, Yung EHK, Lam PTI, Tam CM and Cheung SO (2001) Application of Delphi method in selection of procurement systems for construction projects. Construction Management and Economics 19(7): 699-718.

CIB (International Council for Building) (1999) Agenda 21 on Sustainable Construction. Rotterdam. CIB, Rotterdam, the Netherlands, CIB Report Publication 237.

Considerate Constructors Scheme (2005) Corporate Social Responsibility. Considerate Constructors Scheme, Ware, UK. See http://www.ccscheme.org.uk/index.php/ corporate-social-responsibility (accessed 17/08/2012).

Constructing Excellence (2004) Lean Construction. Constructing Excellence, London, UK. See http://www. constructingexcellence.org.uk/pdf/fact_sheet/lean.pdf (accessed 17/08/2012).

Defra (Department for Environment, Food and Rural Affairs) (2006) Procuring the Future - The Sustainable Procurement Task Force National Action Plan. Defra, London, UK.

Defra (2007) UK Government Sustainable Procurement Action Plan - Incorporating the Government Response to the Report of the Sustainable Procurement Task Force. Defra, London, UK.

Department for Business Innovation and Skills (2012) Corporate Responsibility. BIS, London, UK. See http://www.bis.gov.uk/policies/business-sectors/ green-economy/sustainable-development/corporateresponsibility (accessed 17/08/2012).

DETR (Department of the Environment, Transport and the Regions) (2000) Building a Better Quality of Life: A Strategy for More Sustainable Construction. DETR, London, UK.

Eadie R, McKeown C and Anderson K (2011) The social element of sustainable civil engineering public procurement in Northern Ireland. International Journal of Business and Social Science 2(12): 36-43. 
Environmental Audit Committee (2005) Sustainable Public Procurement Sixth Report of Session 2004-05. Stationery Office, London, UK, HC 266.

GCCP (Government Construction Clients' Panel) (2000) Constructing the Best Government Client: Achieving Sustainability in Construction Procurement Sustainability Action Plan. BRE, Watford, UK. Hallowell MR and Gambatese JA (2010) Qualitative research: application of the Delphi method to CEM research. Journal of Construction Engineering and Management 136(1): 99-107.

Hawkins RGP and Shaw H (2004) Briefing: Sustainable development: a 'monument for eternity'? Proceedings of the Institution of Civil Engineers - Engineering Sustainability 157(1): 3-5.

Henchion M and McIntyre B (2005) Market access and competitiveness issues for food SMEs in Europe's lagging rural regions (LRRs). British Food Journal 107(6): 404-422.

Highways Agency (2003) Building Better Roads: Towards Sustainable Construction. Highways Agency, London, UK. See http://www.highways.gov.uk/aboutus/ documents/better_roads.pdf (accessed 17/08/2012).

Hinks J and McNay P (1999) The creation of a management-by-variance tool for facilities management performance assessment. Facilities 17(1/2): 31-53.

IDeA (2003) Sustainability and Local Government Procurement. Improvement and Development Agency (IDeA), London, UK.

Kenley R, London K and Watson J (2000) Strategic procurement in the construction industry: mechanisms for public sector clients to encourage improved performance in Australia. Journal of Construction Procurement 6(1): 4-19.

Khosrow-Pour M and Herman N (2001) Critical issues of web-enabled technologies in modern organizations. The Electronic Library 19(4): 208-220.

Love PED, Skitmore M and Earl G (1998) Selecting a suitable procurement method for a building project. Construction Management and Economics 16(2): 221-233.

Love PED, Holt GD and Li H (2002) Triangulation in construction management research. Engineering, Construction and Architectural Management 9(4): 294-303.

MacCarthy BL and Atthirawong W (2003) Factors affecting location decisions in international operations a Delphi study. International Journal of Operations \& Production Management 23(7): 794-818.

Martino JP (1983) Technological Forecasting for Decision Making. Elsevier Science, New York, NY, USA.

Meehan J and Bryde D (2011) Sustainable procurement practice. Business Strategy and the Environment 20(2): 94-106.
Mitchell V and McGoldrick PJ (1994) The role of geodemographics in segmenting and targeting consumer markets: a Delphi study. European Journal of Marketing 28(5): 54-72.

Mullen PM (2003) Delphi: myths and reality. Journal of Health Organization and Management 17(1): 37-52.

NAO (National Audit Office) (2005) Improving Public Services through Better Construction. The Stationery Office, London, UK.

OGC (Office of Government Commerce) (2005) Procurement Guide 11: Sustainability. OGC, London, UK.

Preuss L (2009) Addressing sustainable development through public procurement: the case of local government. Supply Chain Management: An International Journal 14(3): 213-223.

Rethinking Construction (2003) Demonstrations of Sustainability. Rethinking Construction, London, UK.

Robinson JBL (1991) Delphi methodology for economic impact assessment. Journal of Transportation Engineering 117(3): 335-349.

Scholl W, Konig C, Meyer B and Heising P (2004) The future of knowledge management: an international Delphi study. Journal of Knowledge Management 8(2): 19-35.

Shon T and Swatman PMC (1998) Identifying effectiveness criteria for Internet payment systems. Internet Research: Electronic Networking Applications and Policy 8(3): 202-218.

Sourani A and Sohail M (2005) Realising social objectives of sustainable construction through procurement strategies. In Proceedings of the CIB W92/T23/W107 International Symposium on Procurement Systems 'The Impact of Cultural Differences and Systems on Construction Performance'. University of Nevada - Las Vegas (UNLV), Las Vegas, Nevada, USA, 8-10 February 2005 (Sullivan K and Kashiwagi DT (eds)). Performance Based Studies Research Group (PBSRG), School of Construction, Arizona State University, Tempe, AZ, USA, pp. 637-644.

Sourani A and Sohail M (2011) Barriers to addressing sustainable construction in public procurement strategies. Proceedings of the Institution of Civil Engineers - Engineering Sustainability 164(4): 229-237.

Sustainable Construction Task Group (2001) Reputation, Risk and Reward: The Business Case for Sustainability in the UK Property Sector. Sustainable Construction Task Group, Centre for Sustainable Construction, BRE, Watford, UK.

Sustainable Procurement Task Force (2006) Procuring the Future - Sustainable Procurement National Action Plan: Recommendations from the Sustainable Procurement Task Force. Defra, London, UK. 
Tan Y, Shen L and Yao H (2011) Sustainable construction practice and contractors' competitiveness: a preliminary study. Habitat International 35(2): 225-230.

Thomson J and Jackson T (2007) Sustainable procurement in practice: lessons from local government. Journal of Environmental Planning and Management 50(3): 421-444.
Walker H and Brammer S (2009) Sustainable procurement in the United Kingdom public sector. Supply Chain Management: An International Journal 14(2): 128-137. Yeung JFY, Chan APC and Chan DWM (2009) Developing a performance index for relationship-based construction projects in Australia: Delphi study. Journal of Management in Engineering 25(2): 59-68.
WHAT DO YOU THINK?

To discuss this paper, please email up to 500 words to the editor at journals@ice.org.uk. Your contribution will be forwarded to the author(s) for a reply and, if considered appropriate by the editorial panel, will be published as a discussion in a future issue of the journal.

Proceedings journals rely entirely on contributions sent in by civil engineering professionals, academics and students. Papers should be 2000-5000 words long (briefing papers should be 1000-2000 words long), with adequate illustrations and references. You can submit your paper online via www.icevirtuallibrary.com/content/journals, where you will also find detailed author guidelines. 